\title{
Proteinases of Pseudomonas aeruginosa Evoke Mucin Release by Tracheal Epithelium
}

\author{
Jeffrey D. Klinger, Bernard Tandler, \\ Carole M. Liedtke, and Thomas F. Boat \\ Cystic Fibrosis Center, Departments of Pediatrics, \\ Developmental Genetics and Anatomy, School of Medicine, \\ Rainbow Babies and Childrens Hospital, and \\ Department of Oral Biology, School of Dentistry, \\ Case Western Reserve University, Cleveland, Ohio 44106
}

bstract. We have determined the potential of exoproducts from pathogenic bacteria to stimulate the release of high molecular weight mucins from goblet cells of airway epithelium in a rabbit tracheal explant system. Culture supernatants from proteolytic strains of Pseudomonas aeruginosa and Serratia marcescens, but not supernatants from a number of non-proteolytic strains, released mucins from goblet cells. Highly purified elastase and alkaline proteinase from $P$. aeruginosa stimulated goblet cell mucin release in a dose-dependent fashion. Lipopolysaccharide, exotoxin $\mathrm{A}$, and alginate of $P$. aeruginosa did not possess mucin release properties. Proteolytic activity was required for mucin release by $P$. aeruginosa elastase, but such release in goblet cells was not mediated by cyclic AMP. Morphologic studies suggested rapid release of mucins from goblet cells in response to elastase by a process resembling apocrine secretion. Several nonbacterial proteinases mimicked the effect of Pseudomonas proteases. These studies provide support for the hypothesis that bacterial and other proteinases play a role in the pathogenesis of mucus hypersecretion in acute and chronic lung infections.

\section{Introduction}

Lung disease in cystic fibrosis $(\mathrm{CF})^{1}$ is characterized by hypersecretion of mucus, mucus plugging of peripheral airways,

Address correspondence to Dr. Klinger, Department of Pediatrics, Case Western Reserve University. Dr. Boat's present address is Department of Pediatrics, University of North Carolina, Chapel Hill, NC 27514.

Received for publication 20 March 1984.

1. Abbreviations used in this paper: $\mathrm{CF}$, cystic fibrosis; $\mathrm{P}_{1}$, initial equilibration period; LPS, lipopolysaccharide; $P_{2}, 15$-min reincubation; TSB, tryptic soy broth.

J. Clin. Invest.

(c) The American Society for Clinical Investigation, Inc. $0021-9738 / 84 / 11 / 1669 / 10 \quad \$ 1.00$

Volume 74, November 1984, 1669-1678 and chronic airways infection (1). It has been difficult to establish whether excess mucus results from factors closely related to the gene defect or is secondary to airways infection. Evidence has been reported which supports both explanations. Specific pathophysiologic mechanisms linking infection and mucus hypersecretion in this disease have not been identified.

Recent evidence from in vitro studies suggests that bacterial exoproducts alter secretory functions of respiratory mucosa. Adler et al. $(2,3)$ demonstrated increased secretion of labeled macromolecules by guinea pig tracheal explants in response to cholera toxin or crude Pseudomonas aeruginosa filtrates. Stutts et al. (4) showed that supernatants from $P$. aeruginosa cultures significantly alter the bioelectric properties and presumably salt and water transport of canine bronchial epithelium. We therefore determined the potential of bacteria commonly associated with CF (1) or other patients with infected airways to stimulate mucin release and examined mechanisms of this effect in a well-characterized rabbit tracheal explant system. Results obtained with culture filtrates of $P$. aeruginosa, Pseudomonas cepacia, Hemophilus influenzae, Klebsiella pneumoniae, and Serratia marcescens, as well as purified bacterial products and mammalian proteinases, form the basis of this report.

\section{Methods}

Bacterial strains and products. Smooth and mucoid isogenic segregants of Pseudomonas aeruginosa were isolated from the sputum of an 11-yr-old CF patient. Both colonial morphologies (DGM, DGS) had the same serotype (International type $6 / 10$ ) by slide agglutination using commercial antisera (Difco Laboratories, Detroit, MI). P. aeruginosa strain PA-103 (serotype 11) was isolated from sputum of an adult nonCF patient and has been used in numerous studies of exotoxin A (5); it was supplied by Dr. P. V. Liu, University of Louisville Health Sciences Center, Louisville, KY. P. aeruginosa strain WR-5, a blood isolate (serotype 12) (6), was supplied by Dr. Barbara Iglewski, University of Oregon Health Sciences Center, Portland, OR. PAKS-18 is the protease-negative ethyl methane sulphonate mutant of the wild-type P. aeruginosa urine isolate PAKS-1 (7). Both of the PAKS strains are serotype 9, and were supplied by Dr. Bengt Wretlind, Karolinska Hospital, Stockholm, Sweden. Pseudomonas cepacia strain $715 \mathrm{j}$ was isolated from the sputum of a 22 -yr-old CF patient. Additional test organisms kindly provided by the Cleveland Clinic Foundation, Cleve- 
land, Ohio, included Klebsiella pneumoniae (derived from American Type Culture Collection Strain 27799), nonpigmented Serratia marcescens (CCF 33), and a serotype B Hemophilus influenzae (CCF 80).

All strains were isolated on tryptic soy agar (TSA), or, in the case of $\boldsymbol{H}$. influenzae, on chocolate agar (Difco Laboratories). Five or six colonies from each isolate were subcultured into 250-ml flasks containing $50 \mathrm{ml}$ tryptic soy broth (TSB; Difco Laboratories) and incubated for $20 \mathrm{~h}$ at $37^{\circ} \mathrm{C}$ in a reciprocating water bath at 140 excursions/min. Broth cultures of $H$. influenzae were grown in TSB that contained $1 \%$ lysed sheep erythrocytes and $1 \%$ Isovitalex supplement (Becton-Dickinson \& Co., Cockeysville, MD). After incubation, bacterial cells were removed by centrifugation at $17,000 \mathrm{~g}$ for $30 \mathrm{~min}$ at $4^{\circ} \mathrm{C}$. Supernatants were sterilized by filtration through $0.22-\mu \mathrm{m}$ nitrocellulose membranes (Nalge Co., Rochester, NY) and immediately frozen at $-20^{\circ} \mathrm{C}$. Supernatant protein concentrations were determined by the Bradford procedure (8) using bovine serum albumin (CFG-7 powder, Reheis Chemical Co., Phoenix, AZ) as standard.

$P$. aeruginosa exotoxin A was purified from highly aerated TBS dialysate cultures of strain PA-103, as described by Taylor and Pollack (9). Exotoxin A preparations were shown to have ADP-ribosyltransferase activity (10), to form a single precipitin line against reference antitoxin in gel immunodiffusion assays, and to possess in vitro toxicity for mouse L-929 cells (11). Exotoxin A was stored at $-70^{\circ} \mathrm{C}$ in $0.01 \mathrm{M}$ Tris buffer, $\mathrm{pH} 8$.

Lipopolysaccharide (LPS) was prepared by trichloroacetic acid extraction of reference International type $6 P$. aeruginosa (strain 1369, supplied by P. V. Liu) using the method of Staub (12). LPS activity was assayed using Limulus amebocyte lysate (Associates of Cape Cod, Inc., Woods Hole, MA). Lyophilized LPS or $1-\mathrm{mg} / \mathrm{ml}$ solutions in pyrogen-free water were stored at $4^{\circ} \mathrm{C}$.

$P$. aeruginosa elastase and alkaline proteinase were obtained commercially (Nagase Biochemicals Ltd., Tokyo, Japan). The purity of each was reconfirmed by demonstration of single bands when $25 \mu \mathrm{g}$ of protein was analyzed by SDS-polyacrylamide gels according to the procedure of Laemmli (13). Lyophilized alkaline proteinase was dissolved in $0.01 \mathrm{M}$ Tris- $\mathrm{HCl}, \mathrm{pH} 8$, aliquoted in $0.1-0.3-\mathrm{ml}$ amounts, and stored at $-20^{\circ} \mathrm{C}$. $P$. aeruginosa elastase was suspended in $3.0 \mathrm{M}$ $\left(\mathrm{NH}_{4}\right)_{2} \mathrm{SO}_{4}, 10 \mathrm{mM}$ sodium acetate, $2.0 \mathrm{mM} \mathrm{CaCl}$, and $0.05 \mathrm{mM}$ $\mathrm{ZnCl}_{2}$, at $\mathrm{pH} 7-8$. As needed, aliquots were dialyzed extensively against $0.01 \mathrm{M}$ Tris- $\mathrm{HCl}, \mathrm{pH} 8$, and stored at $-20^{\circ} \mathrm{C}$. Elastase toxoid was prepared by treatment with $4 \%$ formaldehyde in $0.2 \mathrm{M}$ borate buffer, pH 9 (14). Excess formaldehyde was removed by extensive dialysis against Tris buffer, $\mathrm{pH} 8$. This toxoid was devoid of elastolytic activity, but formed a single precipitin line with rabbit anti-elastase serum in a double diffusion agarose system and retained its electrophoretic properties on SDS polyacrylamide gels.

Proteinase assays, inhibitors, and nonbacterial proteinases. General proteinase activity was assayed using a hide powder azure dye-release method (15). One-tenth-milliliter volumes of culture supernatants and $4.9 \mathrm{ml} 0.01 \mathrm{M}$ Tris buffer, $\mathrm{pH} 8$, were incubated with $20 \mathrm{mg}$ hide powder azure (Sigma Chemical Co., St. Louis, MO) for $45 \mathrm{~min}$ at $37^{\circ} \mathrm{C}$ in a shaking waterbath. Absorbance of dye released by proteinase was measured at $595 \mathrm{~nm}$. Elastase activity was assayed as above except that $0.15 \mathrm{ml}$ of each culture supernatant was incubated with $20 \mathrm{mg}$ orcein-elastin in $2.5 \mathrm{ml}$ Tris buffer, with shaking for $10 \mathrm{~h}$. Released orcein was measured in the filtrate at $590 \mathrm{~nm}(16)$

Purified phosphoramidon (17) was obtained from H. Umezawa, Institute of Microbial Chemistry, Tokyo, Japan. Type XI bovine pancreatic trypsin (diphenyl cartamyl chloride-treated to inactivate chymotrypsin), crystallized porcine pancreatic elastase, and 1,10 phenanthroline ( $o$-phenanthroline) were obtained from Sigma Chemical Co.

Tracheal explant cultures and mucin release assay. Tracheas were removed from $3 \mathrm{~kg}$ male New Zealand white rabbits after intravenous overdose of sodium pentobarbital. The epithelium and underlying connective tissue were dissected from the cartilaginous layer and cut into explants $\sim 2.5 \times 4.0 \mathrm{~mm}$. Typically 20-30 explants were obtained from each trachea. Four explants, randomly selected with respect to donor animal and tracheal location, were cultured in each of 16-24, 35-mm tissue culture dishes containing $1.5 \mathrm{ml}$ medium 199 (Gibco, Grand Island, NY) with $250 \mu \mathrm{g} / \mathrm{ml}$ ticarcillin (Beecham Laboratories, Bristol, TN) and $0.25 \mu \mathrm{g} / \mathrm{ml}$ amphotericin B. The mucous glycoprotein precursor $\mathrm{Na}_{2}{ }^{35} \mathrm{SO}_{4} \quad(20-40 \mu \mathrm{Ci} / \mathrm{ml}$ final concentration; 500 $\mathrm{mCi} / \mathrm{mMol}$, New England Nuclear, Boston, MA) was also added to the culture medium. Plates were incubated in a water-saturated atmosphere of $40 \% \mathrm{O}_{2}$, and $5 \% \mathrm{CO}_{2}$ (balance air) at $35^{\circ} \mathrm{C}(18)$.

After an initial equilibration period $\left(P_{1}\right)$ of $20-24 \mathrm{~h}$ for labeling mucins, media were collected and explants washed with two additional $1.5-\mathrm{ml}$ aliquots of unlabeled medium. Incubation and wash media from each dish were pooled. Potential stimulators of mucin release were then added in fresh unlabeled medium, and dishes were reincubated for $15 \mathrm{~min}\left(\mathrm{P}_{2}\right)$, except in time-course experiments. Control dishes received no additives. Labeled mucins secreted in both periods were isolated from other labeled macromolecules using an automatic BioGel A-5m gel filtration system (19) and counted using appropriate quench correction. DPM of $\mathrm{Na}_{2}{ }^{35} \mathrm{SO}_{4}$ in $0.5 \mathrm{ml}$ of the void volume fraction of $P_{1}$ and $P_{2}$ culture media were $16,440 \pm 410$ (SEM)/24 $h$ and $465 \pm 53$ / 15 min, respectively, in a typical experiment.

A secretory index expressing the relative increase in rate of release of labeled mucins under experimental conditions was calculated for each culture dish as: [dpm per hour during $P_{2}$ (test)/dpm per hour during $P_{1}$ (test)]/[dpm per hour during $P_{2}$ (control)/dpm per hour during $P_{1}$ (control)]. This approach has been used in previous studies $(18,20,21)$. The index theoretically is 1.0 if mucin release is not stimulated or inhibited. Differences between mean secretory indices and 1.0 , i.e., no additives, were analyzed using a one sample $t$ test with an expected numerator value of 1.0 (22). Significance of differences between mean secretory indices of response to different stimulators was calculated using a paired $t$ test.

Ultrastructural studies. Tracheal explants were fixed in culture dishes by addition of an equal volume of phosphate-buffered, fullstrength Karnovsky's (23) fixative to culture medium. The specimens were immediately transferred to fresh half-strength Karnovsky's fixative for $2 \mathrm{~h}$ at room temperature. After rinsing in buffered sucrose, they were postfixed for $2 \mathrm{~h}$ in phosphate-buffered $2 \%$ osmium tetroxide (24). Tissues were rinsed in distilled water and soaked overnight in aqueous $0.25 \%$ uranyl acetate. After another rinse in water, the explants were dehydrated in ethanol and embedded in Epon-Maraglas (25). Thin sections were sequentially stained with methanolic uranyl acetate (26) and lead tartrate (27) and examined in a Siemens Elmiskop 1a electron microscope. For light microscopy, sections $1-\mu \mathrm{m}$ thick were stained with toluidine blue (28) and examined and photographed with a Zeiss Ultraphot II microscope.

Cyclic nucleotides and cAMP assay. Cyclic AMP was measured as previously described (29). Briefly, rabbit tracheal explants were cultured for $24 \mathrm{~h}$ in unlabeled Medium 199 as described for mucin release assays. They were then incubated at $35^{\circ} \mathrm{C}$ for $0.5-10 \mathrm{~min}$ in unlabeled medium containing $0.75-250 \mathrm{mg} / \mathrm{ml}$ of native or heat inactivated $\left(30 \mathrm{~min}, 100^{\circ} \mathrm{C}\right) P$. aeruginosa elastase. To stop the reaction, tubes containing the explants and medium were immersed 
in a boiling water bath for $5 \mathrm{~min}$, then cooled and freeze-thawed. Cyclic AMP levels were measured by the isotope dilution method of Brown et al. (30). Medium harvested from enzyme treated or control explants did not contain measurable amounts of cAMP for incubation times up to $20 \mathrm{~min}$. Hence, this procedure assessed tissue levels of cAMP. Cyclic AMP levels were calculated as picomole per milligram protein and expressed as mean $\pm \mathrm{SE}$. The explants were solubilized in $1 \mathrm{~N} \mathrm{NaOH}$ for determination of protein levels by the method of Lowry et al. (31). ${ }^{3} \mathrm{H}$-cAMP $(34 \mathrm{Ci} / \mathrm{mmol})$ was purchased from New England Nuclear. Dibutryl cAMP and 8-Br-cAMP were purchased from Sigma Chemical Co.

\section{Results}

Bacterial products and mucin release. Supernatants from TSB cultures of 10 strains representing five species of gram negative organisms were tested for their ability to release mucins from rabbit tracheal explants (Table I). The final cell densities were similar (mean colony forming units per milliliter was $1.81 \times 10^{10}$; range $0.55 \times 10^{10}($ PAKS 1$)$ to $3.9 \times 10^{10}[S$. marcescens]). Only supernatants from $P$. aeruginosa and $S$. marcescens effected substantial mucin release at both concentrations tested $(1: 4,1: 16)$.

The supernatant of strain DGS (the smooth segregant of strain DGM) was the most active of any supernatant tested in the mucin release assay. The most stimulatory $P$. aeruginosa strains (DGM, DGS, WR-5, PAKS 1) were highly proteolytic and elastolytic. Elastolytic activity was not strictly related to total supernatant protein concentration. $P$. aeruginosa strains producing small amounts of elastase (PA-103, PAKS 18) showed little if any mucin release. TSB alone did not effect mucin release. Supernatants from other species having unde-

Table I. Stimulation of Mucin Release by Bacterial Culture Supernatants

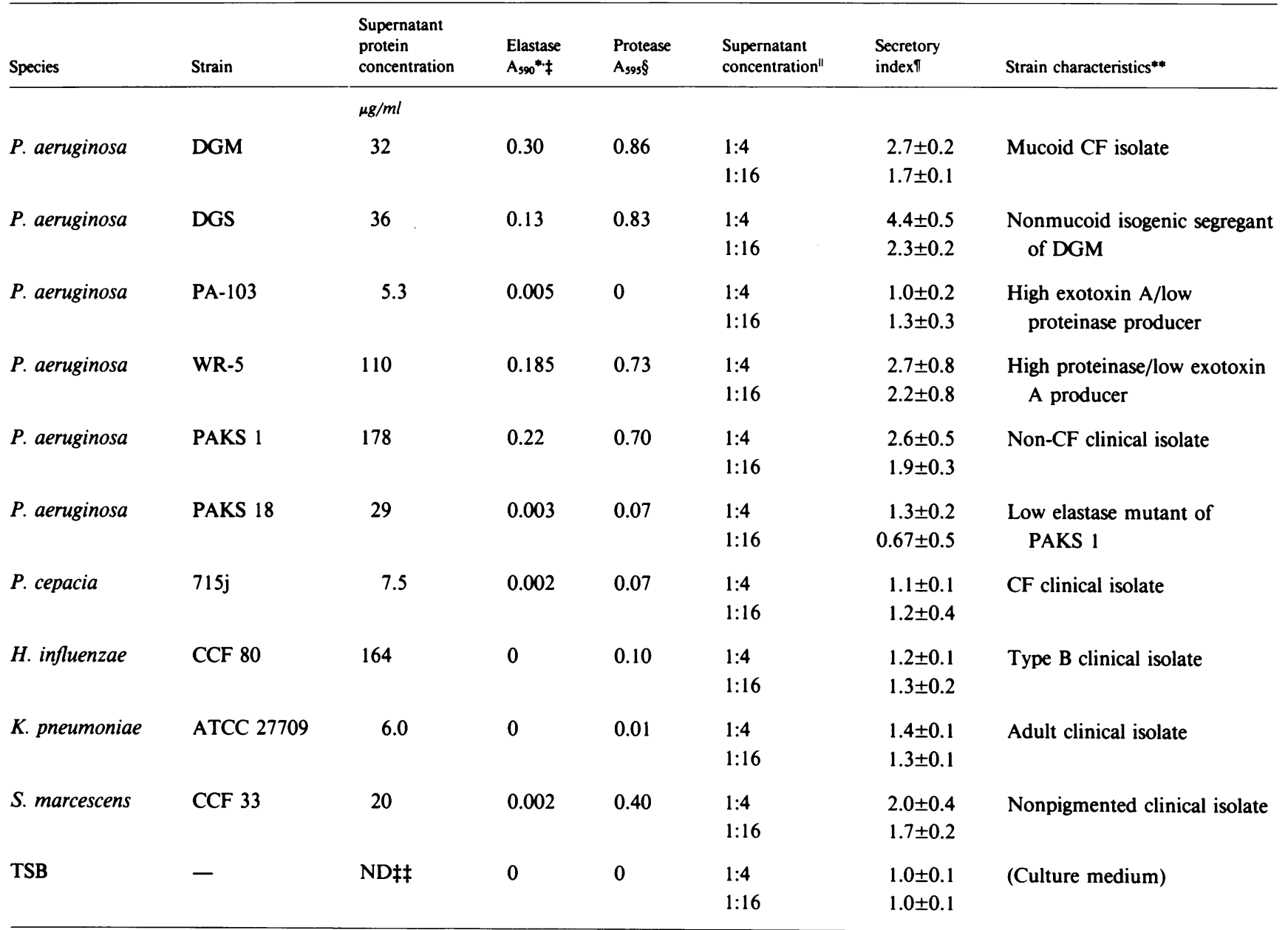

* Assays of undiluted supernatants. $¥ A_{590}$ orcein-elastin assay; $0.15 \mathrm{ml}$ cell-free supernatants. $\S A_{595}$ hide powder azure dye release; $0.1 \mathrm{ml}$ undiluted cell-free supernatant. "Final volume/volume concentration of supernatant to total media volumes. I Mean \pm SEM, minimum of 3-4 repetitions. ** See Methods for detailed description of strains. 
tectable or low levels of proteinases including elastase, i.e., $K$. pneumoniae, $H$. influenzae, $P$. cepacia, also had low stimulatory capacity. The $S$. marcescens supernatant which was moderately proteolytic (virtually no elastase activity) released some mucin, but less than elastolytic $P$. aeruginosa supernatants during the 15-min exposure period. No loss of ciliary motion was seen using a steroscopic microscope (25.2 times) and reflected surface lighting after $15 \mathrm{~min}$ incubation with any culture supernatants.

Four purified $P$. aeruginosa products varied widely in their ability to stimulate mucin release (Table II). Exotoxin A did not release labeled mucins at concentrations approaching probable toxic levels $(10,11)$, even when $P_{2}$ was extended to $0.5,1.0$, or $2.0 \mathrm{~h}$. Lipopolysaccharide extracted from an International serotype 6 organism also failed to release mucins during a 15-min $P_{2}$ interval. At concentrations of $10 \mu \mathrm{g} / \mathrm{ml}$ both Pseudomonas proteinases increased mucin release; the mean secretory index for elastase was significantly greater than that of any of the other three products $(P<0.005)$. Panel $A$ of Fig. 1 shows data for mucin release by tracheal explants in response to $0.1-100 \mu \mathrm{g} / \mathrm{ml}$ of $P$. aeruginosa elastase. The mean secretory index was $1.3 \pm 0.2$ at $0.1 \mu \mathrm{g} / \mathrm{ml}$, and increased to $3.4 \pm 0.3$ at $100 \mu \mathrm{g} / \mathrm{ml}$. Alkaline proteinase likewise gave a dose dependent, but more modest stimulation of mucin release (panel $B$, Fig. 1).

To further substantiate a role for enzymatically active elastase as a stimulator of mucin release we tested four preparations of inactivated or inhibited elastase (Table III). Chelation of magnesium (phenanthroline plus an excess of calcium) reduced the secretory index in response to $40 \mu \mathrm{g} / \mathrm{ml}$ Pseudomonas elastase to $58 \%(P=0.05)$ of that with elastase alone. Likewise, the proteinase inhibitor phosphoramidon at 100 -fold $(P<0.04)$ and 500 -fold $(P<0.01)$ molar excess decreased the secretory index obtained with $10 \mu \mathrm{g} / \mathrm{ml}$ elastase to 32 and $41 \%$, respectively. For these experiments, phosphoramidon and elastase were mixed and preincubated for 15-30 min at room temperature before addition to explants. In the dye release proteinase assay (15), phosphoramidon (100 and $500 \mathrm{M}$ excess) reduced the activity of $P$. aeruginosa elastase $(10 \mu \mathrm{g} / \mathrm{ml}) 29$ and $86 \%$, respectively. Lower concentrations of phosphoramidon did not block mucin release in response to

Table II. Mucin Release in Response to P. aeruginosa Products*

\begin{tabular}{lcc}
\hline Product & Concentration & Secretory index \\
\hline & $\mu g / m l$ & \\
Elastase & 10 & $2.77 \pm 0.2$ \\
Alkaline protease & 10 & $1.88 \pm 0.4$ \\
LPS & 100 & $1.3 \pm 0.2$ \\
Exotoxin A & 0.1 & $1.0 \pm 0.1$ \\
\hline
\end{tabular}
* See Methods for preparation and purity criteria.
$¥$ Mean \pm SEM, 4-14 repetitions.

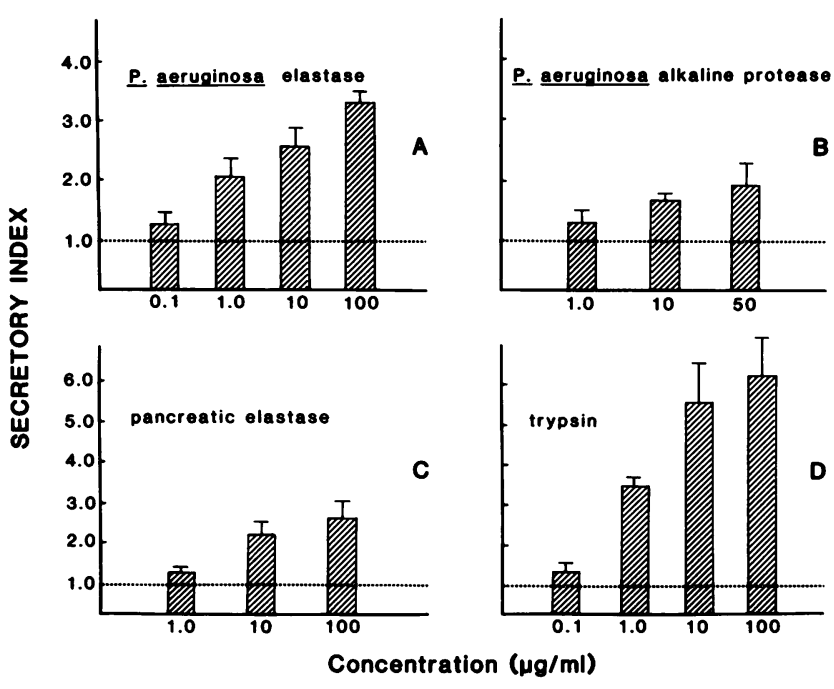

Figure 1. Mucin release by rabbit tracheal explants: dose responses to proteinases. $(A) P$. aeruginosa elastase. $(B) P$. aeruginosa protease.

$(C)$ Porcine pancreatic elastase. $(D)$ Bovine pancreatic trypsin. Error bars show mean secretory index, \pm SEM for 3-15 repetitions.

elastase. A 500 -fold $\mathrm{M}$ excess $(72 \mu \mathrm{g} / \mathrm{ml}$ ) of phosphoramidon alone released little if any mucin.

The mean secretory index in response to elastase toxoid

Table III. Inhibition of P. aeruginosa

Elastase Effect on Mucin Release

\begin{tabular}{|c|c|c|c|}
\hline Additive & $\begin{array}{l}\text { Elastase } \\
\text { concentration }\end{array}$ & $n^{*}$ & $\begin{array}{l}\text { Secretory } \\
\text { index } \neq\end{array}$ \\
\hline & $\mu g / m l$ & & \\
\hline Elastase & 40 & 4 & $3.1 \pm 0.6$ \\
\hline $10 \mathrm{mM}$ calcium & 0 & 4 & $1.8 \pm 0.1$ \\
\hline $\begin{array}{l}\text { Elastase; } 1 \mathrm{mM} \\
\text { phenanthroline, } 10 \\
\mathrm{mM} \text { calcium }\end{array}$ & 40 & 4 & $1.8 \pm 0.2$ \\
\hline $\begin{array}{l}\text { Elastase } \\
72 \mu \mathrm{g} / \mathrm{ml}\end{array}$ & 10 & 3 & $3.7 \pm 0.3$ \\
\hline phosphoramidon§ & 0 & 3 & $1.4 \pm 0.5$ \\
\hline $\begin{array}{l}\text { Elastase; } 14 \mu \mathrm{g} / \mathrm{ml} \\
\text { phosphoramidon }\end{array}$ & 10 & 3 & $2.5 \pm 0.4$ \\
\hline $\begin{array}{l}\text { Elastase; } 72 \mu \mathrm{g} / \mathrm{ml} \\
\text { phosphoramidon }\end{array}$ & 10 & 3 & $2.2 \pm 0.2$ \\
\hline $\begin{array}{l}\text { Elastase } \\
10 \mu \mathrm{g} / \mathrm{ml} \text { elastase }\end{array}$ & 10 & 4 & $1.8 \pm 0.3$ \\
\hline toxoid" & 0 & 4 & $1.0 \pm 0.2$ \\
\hline Elastase & 10 & 4 & $2.7 \pm 0.2$ \\
\hline $\begin{array}{l}\text { Elastase, } 100^{\circ} \mathrm{C}, 10 \\
\min \end{array}$ & 10 & 4 & $1.3 \pm 0.1$ \\
\hline
\end{tabular}

* $n$, number of repetitions.

‡ Mean \pm SEM

$\$ 72 \mu \mathrm{g} / \mathrm{ml}, 500$-fold molar excess (versus elastase concentration).

" Formaldehyde-treated elastase; see Methods. 
was lower than that of native elastase $(P<0.05)$. The preparation of elastase used as control in the toxoid experiment had been frozen and thawed several times and gave lower than expected results (secretory index: $1.8 \pm 0.33$ vs. $2.8 \pm 0.2$ $(n=14)$; see Table I). After five freeze-thaw steps, $P$. aeruginosa elastase retained $70.5 \%$ of the original activity against hide powder azure; after seven freeze-thaw steps only $57.3 \%$ of the activity remained. This lability provided additional evidence that native enzymatic activity is required for mucin release.

Boiling Pseudomonas elastase $(10 \mu \mathrm{g} / \mathrm{ml})$ for $10 \mathrm{~min}$ abolished stimulatory activity $(P<0.005)$. The secretory index obtained with heated elastase was not significantly different than that in control cultures.

Morphologic studies. After incubation for 20-24 h, control specimens of trachea were identical to those fixed immediately after extirpation from anesthetized rabbits (Fig. 2). The structure of the lining epithelium of the rabbit trachea has been described by Konradova (32) and will not be described in detail here. The tracheal epithelium consisted principally of ciliated, goblet cells, and basal cells. These cells were closely coherent. Goblet cells were abundant and had prominent thecas distended by numerous secretory granules. Only a few goblet cells $(<15 \%)$ showed evidence of mucous discharge; such cells were characterized by bulging of their apical surface into the lumen, which created a "dome." Empty or nascent goblet cells were sparse in controls. These cells had at most only a few mucous droplets, and therefore a slender, columnar silhouette.

After exposure to $P$. aeruginosa elastase, specimens at all time points evidenced a similar spectrum of responses related to mucus discharge (Figs. 3 and 4). Between 55 and $100 \%$ of the goblet cells that abutted the lumen were domed. Moreover, many of the domes were elongated and contorted and contained most of the mucous droplets remaining in the cell (Figs. 5 and 6). Many of the stimulated specimens displayed detached pieces of goblet cells or free cytoplasmic tags. Few full goblet

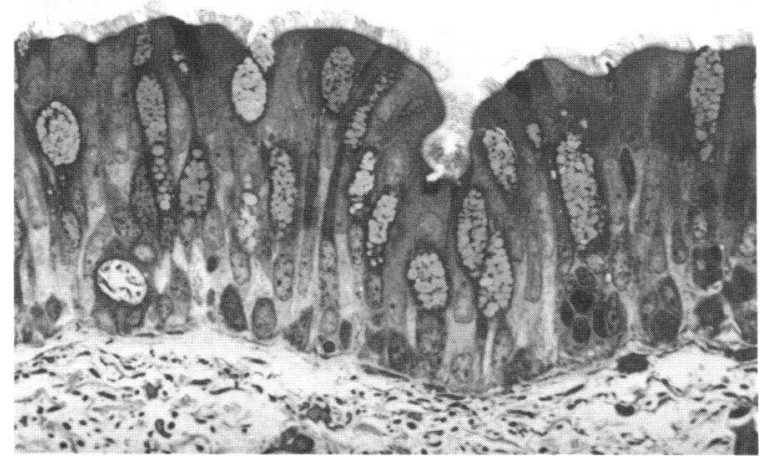

Figure 2. Photomicrograph of untreated rabbit trachea maintained in organ culture for $20 \mathrm{~h}$. The pseudostratified epithelium is intact. Goblet cells, characterized by large numbers of mucus droplets, are abundant. Toluidine blue. $\times 360$.

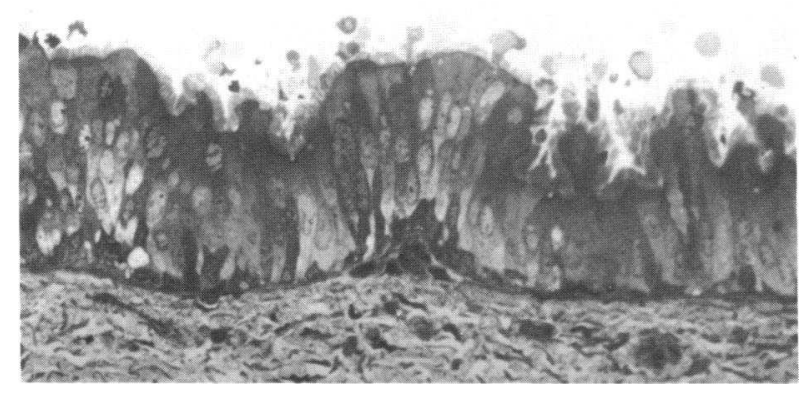

Figure 3. Rabbit trachea five min after exposure to $10 \mu \mathrm{g} P$. aeruginosa elastase. Masses of detached cytoplasm are present along the epithelial surface, as are cytoplasmic protrusions of goblet cells. Toluidine blue. $\times 230$.

cells remained; most were completely exhausted of their secretory content, extremely attenuated, and had high cytosolic density. Regardless of the secretory status of the goblet cells, their junctions with adjacent ciliated cells were unaltered, and all epithelial lining cells were closely adherent (Fig. 7).

Cyclic AMP. Fig. 8 depicts changes with time in cAMP levels in response to $28 \mu \mathrm{g} / \mathrm{ml}$ elastase. Basal cAMP levels of $10 \mathrm{pmol} / \mathrm{mg}$ protein increased to $15 \mathrm{pmol} / \mathrm{mg}$ protein during the first $3 \mathrm{~min}$ of incubation. The tissue cAMP content decreased to basal levels after $5 \mathrm{~min}$ and remained there for incubation times up to $90 \mathrm{~min}$. Heat-inactivated elastase did not alter cAMP levels in explants. As seen in Table IV, $P$. aeruginosa elastase effected a small dose-dependent increase of cAMP levels. Maximal response was attained with $75 \mu \mathrm{g}$ elastase $/ \mathrm{ml}$. This pattern is unlike that for mucin release in response to enzyme, which did not plateau at concentrations of Pseudomonas elastase up to $100 \mu \mathrm{g} / \mathrm{ml}$, and suggests that increased cAMP is not directly related to accelerated release of mucous glycoproteins.

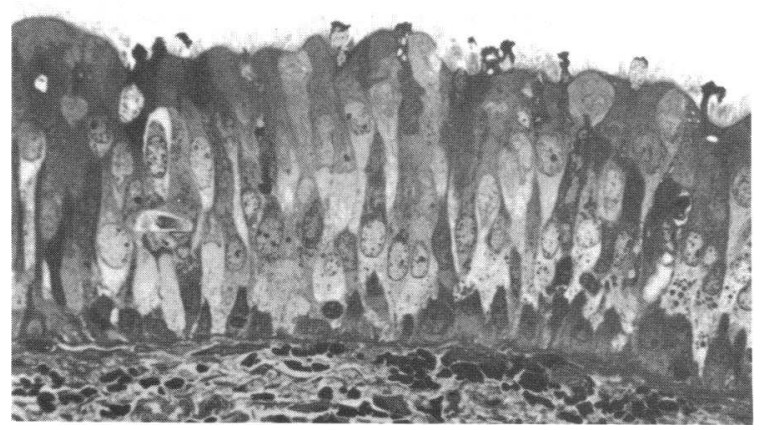

Figure 4. Rabbit trachea $30 \mathrm{~min}$ after exposure to $10 \mu \mathrm{g} P$. aeruginosa elastase. No full goblet cells remain. Many cells still show apical protrusions. Toluidine blue. $\times 360$. 


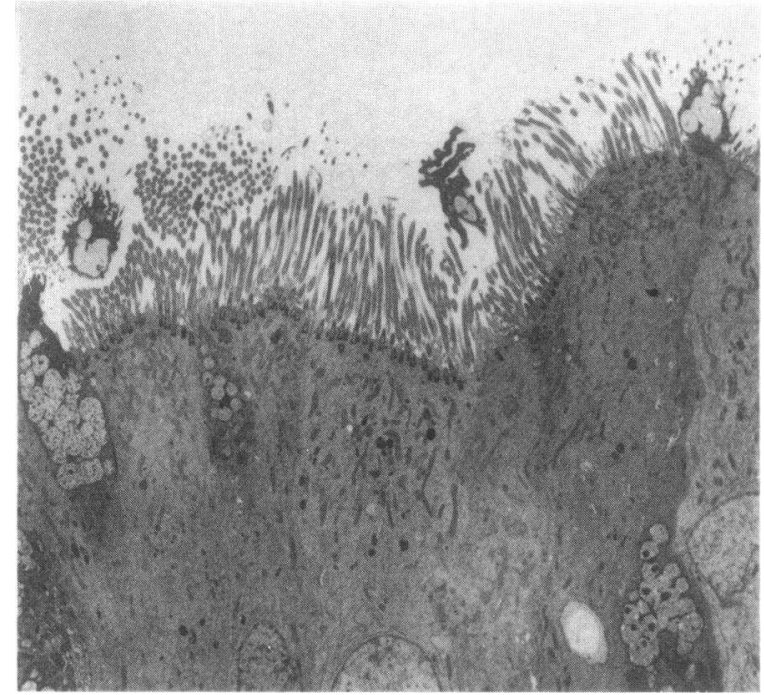

Figure 5. Electron micrograph of trachea $30 \mathrm{~s}$ after exposure to $10 \mu \mathrm{g}$ $P$. aeruginosa elastase. Several detached pieces of cytoplasm containing mucous droplets are free in the lumen. The epithelium is otherwise intact. $\times 1,900$.

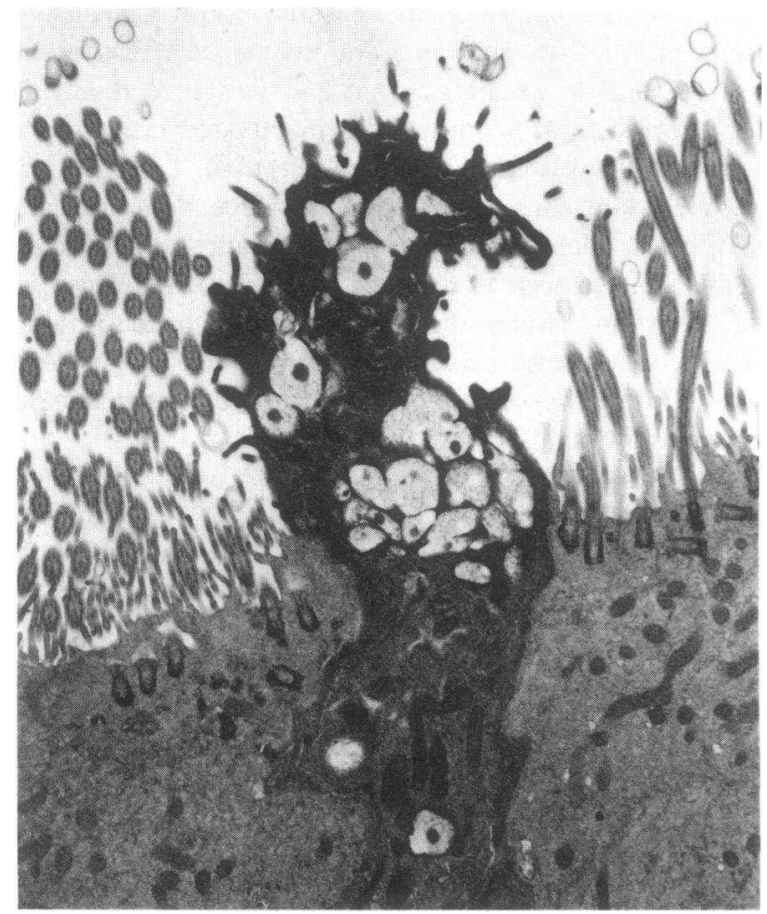

Figure 6. Electron micrograph of the apex of a goblet cell $30 \mathrm{~s}$ after exposure to $10 \mu \mathrm{g}$ elastase. The cell protrudes into the lumen and is quite distorted. Some mucous droplets are still present, but the cytosol is unusually dense. Despite its obvious morphological alteration, this cell maintains its junctional connections and relationships with the flanking ciliated cells. $\times 6,500$.

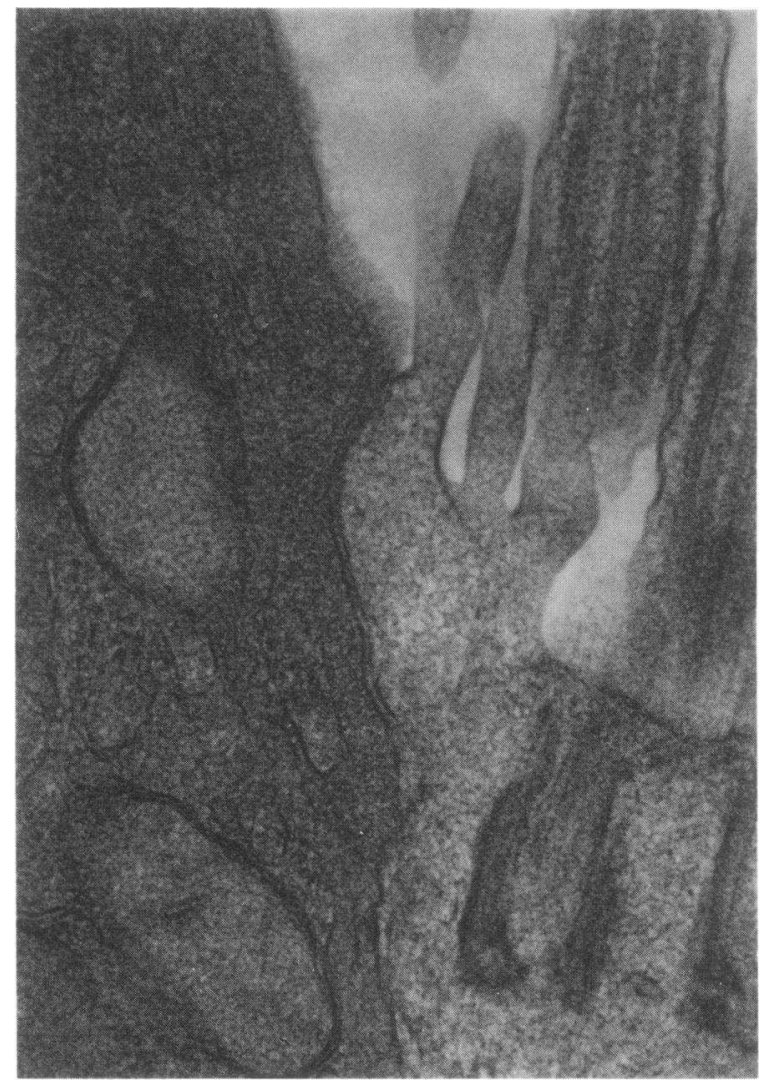

Figure 7. High magnification micrograph of the junctional region of a discharging goblet cell (left) and a ciliated cell (right). The tight junction has maintained its morphological integrity. $10 \mu \mathrm{g}$ elastase, 30 s. $\times 56,000$.

Additionally, exogenous cAMP failed to increase mucin release. Dibutryl-cAMP at concentrations of $10^{-5}-10^{-3} \mathrm{M}$ caused no increase in secretory index after $15 \mathrm{~min}$ of incubation (secretory index $=1.02 \pm 0.05, n=3$ repetitions). Similar absence of effect was obtained using $10^{-5}-10^{-3} \mathrm{M}$ 8-Br-cAMP.

Mammalian proteinases. Both porcine pancreatic elastase and chymotrypsin-free bovine pancreatic trypsin stimulated

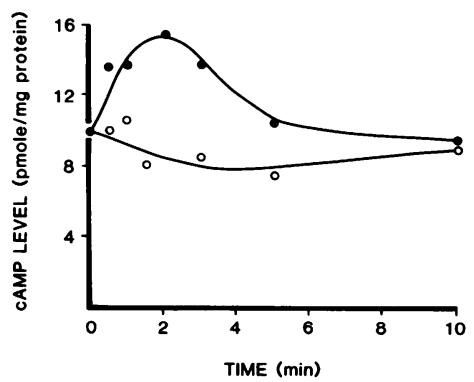

Figure 8. Effect of P. aeruginosa elastase on CAMP levels in rabbit tracheal explants. Explants were incubated for the indicated times with elastase $(\bullet)$ or heat-inactivated elastase ( 0 ) at a final concentration of $28 \mu \mathrm{g} / \mathrm{ml}$. Each data point represents the mean of 4-6 determinations. Standard errors of each data point are $<20 \%$ of the means. 
Table IV. Effect of $P$. aeruginosa

Elastase on Adenylate Cyclase Activity

\begin{tabular}{llll}
\hline & $\begin{array}{l}\text { Elastase } \\
\text { concentration }\end{array}$ & $\begin{array}{l}\text { cAMP level } \\
\text { (pmol/mg } \\
\text { protein) }\end{array}$ & \\
Addition & 0 & $10.0 \pm 2.0(4)^{*}$ & \\
\hline Basal (none) & $0.75 \mu \mathrm{g} / \mathrm{ml}$ & $8.4 \pm 0.6(3)$ & $P<0.05$ \\
$\begin{array}{l}\text { P. aeruginosa } \\
\text { elastase }\end{array}$ & $7.5 \mu \mathrm{g} / \mathrm{ml}$ & $10.6 \pm 1.0(3)$ & $\mathrm{NS}$ \\
& $25 \mu \mathrm{g} / \mathrm{ml}$ & $11.9 \pm 0.7(3)$ & $P<0.05$ \\
& $75 \mu \mathrm{g} / \mathrm{ml}$ & $12.8 \pm 1.8(3)$ & $\mathrm{NS} \ddagger$ \\
& $250 \mu \mathrm{g} / \mathrm{ml}$ & $11.9 \pm 0.5(3)$ & $P<0.0005$ \\
& & & \\
\hline
\end{tabular}

* Mean $\pm \mathrm{SE}$; number in parentheses is number of repetitions.

NS, not significant. Levels of significance determined by $t$ test for paired samples (test vs. basal).

$\ddagger$ Large SE.

mucin release in a dose-dependent fashion over the concentration range tested (panels $C$ and $D$, Fig. 1). Of all the proteinases assayed in this study, trypsin was the most potent stimulator of mucin release.

\section{Discussion}

We have demonstrated that extracellular proteinases of $P$. aeruginosa stimulate mucin release by goblet cells in rabbit tracheal epithelium. Thus, proteinases can be added to a growing list of substances which trigger the release of mucins onto the airways surface, including autonomic agonists (21, $33,34)$, polypeptides $(35,36)$, metabolites of arachadonic acid (37), cholera toxin (2), and serum components (18).

The impetus for our studies came from the observation of Adler et al. (3) that sterile culture filtrates of some $P$. aeruginosa strains effect 1.3-1.8-fold increases of labeled macromolecule secretion by guinea pig tracheal explants. Our studies confirm their basic observation, ascertain that the secretory effect specifically involves release of high molecular weight mucins, and identify exoproducts which mediate this effect. Our data support the suggestion that the secretory effect is not evoked by extracellular polyuronic acid (alginate) of mucoid $P$. aeruginosa (3). In addition, we have demonstrated that exotoxin A and lipopolysaccharide do not promote mucin release. Organisms of the same serotype may or may not generate mucin release activity, precluding a strict relationship between these properties.

Four proteolytic strains of $P$. aeruginosa elaborated mucin release activity, while two strains which produced minimal amounts of proteinases did not. This observation, coupled with the demonstration that highly purified elastase and to a lesser extent purified alkaline proteinase from $P$. aeruginosa stimulate mucin release, strongly suggest that proteinases are important, if not the sole products of this organism with mucin release properties. Adler et al. (3) reported that the effect of $P$. aeruginosa filtrates on macromolecule release is stable at $90^{\circ} \mathrm{C}$ for $30 \mathrm{~min}$, a condition which would be expected to inactivate elastase and other proteinases. In fact, in our studies, enzymatic and mucin release activity of $P$. aeruginosa elastase were completely lost after treatment at $100^{\circ} \mathrm{C}$ for $10 \mathrm{~min}$. Differing results of the two heat inactivation studies could relate to species differences in modulation of secretory responses. In addition, Adler's assay system measured all labeled secretory macromolecules, while our assay specifically quantitated the release of high molecular weight mucins (19) and may have been more sensitive to proteinase effects. Finally, we have not exhaustively eliminated the possibility that a bacterial exoproduct other than proteinases might participate in the mucin release response.

Mucins secreted in our in vitro system by rabbit tracheal epithelium are labeled with ${ }^{3} \mathrm{H}$-glucosamine to a constant specific activity within $12 \mathrm{~h}$ (data not shown). Therefore, we have assessed release of all high molecular weight mucins rather than a select pool of these glycoproteins. Addition of radiolabeled precursor to medium only during the initial culture period $\left(P_{1}\right)$ precludes the contribution of newly synthesized mucin to the secreted product during $P_{2}$. Consequently, we have examined only the release of preformed mucins in the studies. Rabbit trachea contains no, or only rudimentary, glands (18). This ensures that the mucin secretory response is a function of surface epithelium and presumably of its goblet cells. Additional studies are required to assess whether proteinases promote mucin biosynthesis or secretory activity of gland cells.

We have partially characterized the mechanism of action of proteinases on mucin-secreting cells. Several pieces of evidence firmly support a conclusion that proteolytic activity is required for the mucin release effect. Heat denaturation, or formaldehyde inactivation of enzyme activity with preservation of immunogenicity, completely abolish mucin release activity of $P$. aeruginosa elastase. In addition, removal of $\mathrm{Zn}+{ }^{2}$ from the assay system with phenanthroline under conditions of calcium sufficiency significantly diminished the activity of this metalloproteinase (38). This approach was required because the simple addition of EDTA or other chelators of divalent cations alters the secretory response of tracheal epithelium (39). Finally, phosphoramidon, a competitive inhibitor of $P$. aeruginosa elastase and other metalloproteinases (17), significantly reduced mucin-release activity.

Results of our studies argue against generalized cytotoxic effects as a mechanism for release of labeled mucins. Specifically, we observed no damage to tracheal cells and no disruption of the integrity of surface epithelium. Ciliary motion was maintained during 15-min exposure periods at all concentrations of enzymes used.

Electron microscopic observations suggest goblet cell mucins are released rapidly in response to proteinases by a process resembling apocrine secretion. Masses of cytoplasm are expelled rapidly from goblet cells, and are accompanied by blebbing and distortion of their apical regions. The manner in which goblet cells release their secretory product has been a matter 
of controversy. Originally, it was thought that goblet cells extrude a single mass of mucus through a break in the apical plasma membrane (40-45). Subsequent studies of intestinal goblet cells by Specian and Neutra (46) have demonstrated compound exocytosis which can be evoked by a variety of secretagogues (47). A similar sequence has been observed in goblet cells of the cat trachea (Tandler, B., unpublished observations). Trier and Rubin (48) have also noted that merocrine secretion is the norm in intestinal goblet cells, but that apocrine secretion occurs after a potent secretory stimulus. We suggest that proteinases similarly may be potent stimuli for goblet cells in large airways. This stimulus could be triggered by proteolytic modification of cell membrane proteins, although currently there is no evidence for such a mechanism.

A number of serine proteinases, including trypsin, chymotrypsin, pronase; subtilisin, protease from Streptomyces griseus, and a 30,000-mol wt proteinase from Pseudomonas maltophilia $(49,50)$, stimulate adenylate cyclase. We found that $P$. aeruginosa elastase also increases cyclic AMP levels in rabbit tracheal epithelium, although the response is a small one. On the other hand, mucin secretion by rabbit trachea is refractory to cyclic AMP analogues which enter these cells and which promote mucin release in cat tracheal explants (20). Therefore, it is highly unlikely that cAMP is an intracellular messenger of the proteinase effect on goblet cells. In this respect the response to proteinases is similar to the secretory response to cholera toxin by guinea pig tracheal explants (2).

Our work suggests that a broad range of proteinases has mucin release effects. $P$. aeruginosa elastase is a metalloproteinase with substrate specificity for peptides that contain a $P_{1}^{\prime}$ leucyl or phenylalányl residue, similar to thermolysin (51). On the other hand' the serine proteinases, pancreatic elastase, and trypsin act on primary specificities of $\mathrm{Ala}(\mathrm{Ser})$-, and $\operatorname{Arg}($ Lys)-, on the carboxyl side of hydrolyzed bonds, and are less potent and considerably more potent, respectively, than $P$. aeruginosa elastase in the mucin release assay. More work is required to establish the relationship between substrate specificity and the response of goblet cells to proteolytic enzymes.

$P$. aeruginosa is a pathogen associated with both acute and chronic lung disease (52). For example, the airways of most patients with cystic fibrosis are permanently colonized with this organism (53). Several potential mechanisms for pathogenicity related to production of proteinases by $P$. aeruginosa in these conditions are recognized. $P$. aeruginosa elastase degrades a number of complement components (54) and IgG (55), which potentially reduces immunologic responses at the epithelial surface. $P$. aeruginosa elastase and other proteinases also may degrade structural elements in the airway walls and lead to bronchiectasis, bronchiolectasis, and air space enlargement (56). Finally, these studies strongly suggest that $P$. aeruginosa proteinases contribute to mucus hypersecretion and obstruction to airflow, both acutely and chronically. In addition, failure to clear excessive mucus may promote ongoing airways infection and set up a troublesome cycle of events.
Under most circumstances the airways are protected from proteolytic effects by antiproteinases, such as the bronchial proteinase inhibitor, which is secreted locally $(57,58)$, and $\alpha_{1}$-antiproteinase, which is acquired from serum by transudation (59). However, $P$. aeruginosa elastase complexes with and inactivates both $\alpha_{1}$-antiproteinase (60) and the bronchial proteinase inhibitor. In fact $P$. aeruginosa elastase can release neutrophil elastase from complexes with the bronchial inhibitor (61). Therefore, one pathogenetic role of $P$. aeruginosa proteinases may be to render normal protective mechanisms inoperative, thus promoting the damaging effects of proteinases released by inflammatory cells. $P$. aeruginosa proteinases probably do not play a role in the ciliary inhibition (62) or in alterations of epithelial ion transport (4) which have been produced by sterile filtrates of $P$. aeruginosa culture media. Both of these activities are heat stable and possess other characteristics which distinguish them from a proteinase effect.

Organisms other than $P$. aeruginosa produce proteinases and could be responsible for acute and chronic mucus hypersecretion. We found that a $S$. marcescens filtrate also was proteolytic and triggered the release of goblet cell mucins. This is consistent with the demonstration of metalloproteinase production by this organism (63). As prepared for these experiments, supernatants from strains of $P$. cepacia, $H$. influenzae, and $K$. pneumoniae did not contain proteinases or mucin release activity in vitro. However, some strains of these organisms may be proteolytic under different conditions. Indeed, we have preliminary data showing that after long periods in culture, e.g., $>26 \mathrm{~h}, P$. cepacia strain $715 \mathrm{j}$ produces extracellular proteinase.

Additionally, proteinase production could be induced in vivo in strains which are not proteolytic in vitro; if so, the effect which we have described may have more pathophysiologic significance than our data currently suggest.

Instillation of proteinases into airways of laboratory animals produces emphysema, and is accompanied by striking goblet cell hyperplasia and metaplasia of conducting airways (64). We propose that intense or prolonged stimulation of mucin secretion by uninhibited proteinases may promote goblet cell proliferation and differentiation of small airways epithelium to a mucus-secreting type. Such changes may occur not only in laboratory animals treated with proteinases, but also in the chronic bronchitis and/or bronchiolitis produced by persisting airways infection. Specifically, in chronic $P$. aeruginosa infection in cystic fibrosis, release of bacterial enzymes may provide this stimulus, most likely in concert with inflammatory cell proteinases (65). Thus, the impressive mucus hypersecretion in airways of cystic fibrosis patients may relate to increased numbers of mucus-secreting units as well as an ongoing source of stimulation for mucus release, both attributable, at least in part, to persistent endobronchial infection.

We wish to emphasize that the implications of our data for alterations of airway structure and function in human lung infections are not yet established. In preliminary experiments, culture supernatant from $P$. aeruginosa (strain-DGS) increased 
mucin secretion from explants of human nasal polyp epithelium as much as 2.4-fold. Additional studies are required to characterize this effect on human airways epithelium.

\section{Acknowledgments}

We thank I. Polony, S. Klayman, and C. Ayala for technical assistance.

These studies were supported in part by grants from the National Institutes of Health (AM 08305), and the Cystic Fibrosis Foundation.

\section{References}

1. Wood, R. E., T. F. Boat, and C. F. Doershuk. 1976. Cystic fibrosis: state of the art. Am. Rev. Resp. Dis. 113:833-878.

2. Adler, K. B., D. H. Hardwick, and J. E. Craighead. 1981. Effect of cholera toxin on secretion of mucin by explants of guinea pig trachea. Lab. Invest. 45:372-377.

3. Adler, K. B., W. C. Winn, T. V. Alberghini, and J. E. Craighead. 1983. Stimulatory effect of Pseudomonas aeruginosa on mucin secretion by respiratory epithelium. J. Am. Med. Assoc. 249:1615-1617.

4. Stutts, M. J., L. F. Guyman, and R. C. Boucher. 1982. Interaction of Pseudomonas aeruginosa products with bronchial epithelia. Chest. 81:13S-14S.

5. Liu, P. V. 1973. Exotoxin of Pseudomonas aeruginosa. I. Factors that influence the production of exotoxin-A. J. Infect. Dis. 128:506513.

6. Baltimore, R. S., A. S. Dobek, F. R. Stark, and M. S. Artenstein. 1974. Clinical and epidemiological correlates of Pseudomonas typing. J. Infect. Dis. 130(Suppl.):553-559.

7. Wretlind, B., and T. Kronevi. 1978. Experimental infections with protease-deficient mutants of Pseudomonas aeruginosa in mice. J. Med. Microbiol. 11:145-154.

8. Bradford, M. M. 1976. A rapid and sensitive method for the quantitation of microgram quantities of protein utilizing the principle of protein-dye binding. Anal. Biochem. 72:248-254.

9. Taylor, N. S., and M. Pollack. 1978. Purification of Pseudomonas exotoxin by affinity chromatography. Infect. Immun. 14:66-70.

10. Iglewski, B. H., and J. C. Sadoff. 1979. Toxin inhibition of protein synthesis: production, purification, and assay of Pseudomonas aeruginosa toxin A. Methods Enzymol. 60:780-793.

11. Middlebrook, J. L., and R. B. Dorland. 1977. Response of cultured mammalian cells to exotoxins of Pseudomonas aeruginosa and Corynebacterium diphtheriae: differential cytotoxicity. Can. J. Microbiol. 23:183-189.

12. Staub, A. M. 1967. Preparation of cell wall antigens from gram-negative bacteria. In Methods in Immunology and Immunochemistry. Vol. I. C. A. Williams and M. W. Chase, editors. Academic Press, Inc., New York. 28-34.

13. Laemmli, U. K. 1970. Cleavage of structural proteins during the assembly of the head of bacteriophage T4. Nature (Lond.). 224:680685.

14. Homma, J. Y., C. Abe, K. Tanamoto, Y. Hirao, K. Morihara, H. Tsuzuki, R. Yanagawa, E. Honda, Y. Aoi, Y. Fujimoto, M. Goryo, N. Imazeki, H. Noda, A. Goda, S. Takeuchi, and T. Ishihara. 1978. Effectiveness of immunization with single and multicomponent vaccines prepared from a common antigen (OEP), protease and elastase toxoids of Pseudomonas aeruginosa on protection against hemorrhagic pneumonia in mink due to P. aeruginosa. Japan. J. Exp. Med. 48:111133.
15. Rinderknecht, H., M. C. Geokas, P. Silverman, and B. J. Haverback. 1968. A new ultrasensitive method for the determination of proteolytic activity. Clin. Chem. Acta. 21:197-203.

16. Johnson, G. C., J. M. Morris, and R. S. Berk. 1967. The extracellular protease from Pseudomonas aeruginosa exhibiting elastase activity. Can. J. Microbiol. 13:711-719.

17. Morihara, K., and H. Tsuzuki. 1978. Phosphoramidon as an inhibitor of elastase from Pseudomonas aeruginosa. Japan. J. Exp. Med. 48:81-84.

18. Boat, T. F., I. Polony, and P. W. Cheng. 1982. Mucin release from rabbit tracheal epithelium in response to sera from normal and cystic fibrosis subjects. Pediatr. Res. 16:792-797.

19. Cheng, P. W., J. M. Sherman, T. F. Boat, and M. Bruce. 1981. Quantitation of radiolabeled mucin glycoproteins secreted by tracheal explants. Anal. Biochem. 117:301-306.

20. Liedtke, C. M., S. A. Rudolph, and T. F. Boat. 1983. $\beta$-adrenergic modulation of mucin secretin in cat trachea. Am. J. Physiol. 244:C391-C398.

21. Shelhamer, J. H., Z. Marom, and M. Kaliner. 1980. Immunologic and neuropharmacologic stimulation of mucous glycoprotein release from human airways in vitro. J. Clin. Invest. 66:1400-1408.

22. Colton, T. E. 1974. Statistics in Medicine. Little, Brown, and Co., Boston. 131.

23. Karnovsky, M. J. 1965. A formaldehyde-glutaraldehyde fixative of high osmolality for use in electron microscopy. J. Cell Biol. 27:137A. (Abstr.)

24. Millonig, G. 1961. Advantages of a phosphate buffer for $\mathrm{OsO}_{4}$ solutions in fixation. J. Appl. Physics. 32:1636. (Abstr.)

25. Tandler, B., and R. J. Walter. 1977. Epon-Maraglas embedment for electron microscopy. Stain Technol. 52:238-239.

26. Stempak, J. G., and R. T. Ward. 1964. An improved staining method for electron microscopy. J. Cell. Biol. 22:697-701.

27. Millonig, G. 1961. A modified procedure for lead staining of thin sections. J. Biophys. Biochem. Cytol. 11:736-739.

28. Björkman, N. 1962. Low magnification electron microscopy in histological work. Acta Morphol. Neerl. Scand. 4:344-348.

29. Liedtke, C. M., T. F. Boat, and S. A. Rudolph. 1982. Neurohormonal receptors and cyclic AMP-binding proteins in rabbit tracheal mucosa-submucosa. Biochim. Biophys. Acta. 719:169-177.

30. Brown, B. L., R. P. Ekins, and J. D. M. Albano. 1972. Saturation assay for cyclic AMP using endogenous binding protein. Adv. Cyclic Nucleotide Res. 2:25-40.

31. Lowry, O. H., N. J. Rosebrough, A. L. Farr, and R. J. Randall. 1951. Protein measurement with the folin reagent. J. Biol. Chem. 193:265-275.

32. Konradova, V. 1966. The ultrastructure of the tracheal epithelium in the rabbit. Folia Morphol. (Prague). 14:210-214.

33. Boat, T. F., and J. I. Kleinerman. 1975. Human respiratory tract secretions. 2. Effect of cholinergic and adrenergic agents on in vitro release of protein and mucous glycoprotein. Chest. 67:32s-34s.

34. Nadel, J. A., and B. David. 1980. Parasympathetic and sympathetic regulation of secretion from submucosal glands in airways. Fed. Proc. 39:3075-3079.

35. Baker, A. P., L. M. Hillegass, D. A. Holden, and W. J. Smith. 1977. Effect of Kallidin, Substance P, and other basic polypeptides on the production of respiratory macromolecules. Am. Rev. Resp. Dis. 115:811-817.

36. Peatfield, A. C., P. J. Barnes, C. Bratcher, J. A. Nadel, and B. Davis. 1983. Vasoactive intestinal peptide stimulates tracheal submucosal gland secretion in ferret. Am. Rev. Respir. Dis. 128:89-93. 
37. Marom, Z., H. Shelhamer, and M. Kaliner. 1981. Effects of arachidonic acid, monohydroxy-eicosatetraenoic acid, and prostaglandins on the release of mucous glycoproteins from human airways in vitro. J. Clin. Invest. 67:1695-1702.

38. Morihara, K., and H. Tsuzuki. 1975. Pseudomonas aeruginosa elastase, affinity chromatography and some properties as a metalloneutral proteinase. Agric. Biol. Chem. (Tokyo). 39:1123-1128.

39. Sherman, J. M., P. W. Cheng, B. Tandler, and T. F. Boat. 1981. Mucous glycoproteins from cat tracheal goblet cells and mucous glands separated with EDTA. Am. Rev. Resp. Dis. 124:476-479.

40. Rhodin, J. A. G. 1966. Ultrastructure and function of the human tracheal mucosa. Am. Rev. Resp. Dis. 93(Suppl.):1-15.

41. Florey, H. W. 1960. Electron microscopic observations on goblet cells of the rat's colon. Quart. J. Exp. Physiol. Cogn. Med. Sci. 45:329-336.

42. Bierring, F. 1962. Electron microscopic observations on the mucus production in human and rat intestinal goblet cells. Acta Pathol. Microbiol. Scand. 54:241-252.

43. Hollmann, K. H. 1963. The fine structure of the goblet cells in the rat intestine. Ann. NY Acad. Sci. 106:545-554.

44. Freeman, J. A. 1962. Fine structure of the goblet cell mucous secretory process. Anat. Rec. 144:341-358.

45. Freeman, J. A. 1966. Goblet cell fine structure. Anat. Rec. 154:121-148.

46. Specian, R. D., and M. R. Neutra. 1980. Mechanism of rapid mucus secretion in goblet cells stimulated by acetylcholine. $J$. Cell. Biol. 85:626-640.

47. Neutra, M. R., L. J. O'Malley, and R. D. Specian. 1982. Regulation of intestinal goblet cell secretion. II. A survey of potential secretagogues. Am. J. Physiol. 242:G380-G387.

48. Trier, J. S., and C. E. Rubin. 1965. Electron microscopy of the small intestine: a review. Gastroenterology. 49:574-603.

49. Richert, N. D., T. A. Bramley, and R. J. Ryan. 1977. Hormone binding, proteases and the regulation of adenylate cyclase activity. In Novel Aspects of Reproductive Physiology. C. H. Spilman and J. W. Wilks, editors. SP Medical and Scientific Books, New York. 81-105.

50. Pinkett, M. O., G. J. Strewler, and W. B. Anderson. 1979. Stimulation of adenylate cyclase activity by a protease which activates cyclic nucleotide phosphodiesterase. Biochem. Biophys. Res. Commun. 90:1159-1165.

51. Morihara, K., H. Tsuzuki, and T. Oka. 1968. Comparison of the specifities of various neutral proteinases from microorganisms. Arch. Biochem. Biophys. 123:572-588.

52. Reynolds, H. Y., and R. B. Fick. 1980. Pseudomonas aeruginosa pulmonary infections (emphasizing nosocomial pneumonia and respiratory tract infections in cystic fibrosis). In Pseudomonas aeruginosa:
The Organism, Diseases It Causes, and Their Treatment. L. D. Sabath, editor. Hans Huber, Bern, Switzerland. 71-88.

53. Høiby, N., and P. O. Schøitz, editors. 1982. Pulmonary infections in cystic fibrosis. Acta Paediatr. Scand. Suppl. 301:1-132.

54. Schultz, D. R., and K. D. Miller. 1974. Elastase of Pseudomonas aeruginosa: inactivation of complement components and complementderived chemotactic and phagocytic factors. Infect. Immun. 10:128135.

55. Döring, G., H.-J. Obernesser, and K. Botzenhart. 1981. Extracellular toxins of Pseudomonas aeruginosa. II. Effect of two proteases on human immunoglobulins IgG, IgA and secretory IgA. Zentralbl. Baktériol. [A]. 249:89-98.

56. Tomashefski, J. F., Jr., M. Bruce, L. Poncz, J. D. Klinger, and D. G. Dearborn. 1984. Alterations of lung elastic tissue in cystic fibrosis. Am. J. Clin. Pathol. 81:805-806. (Abstr.)

57. Franken, C., V. A. Kramps, C. Meyer, and J. H. Dijkman. 1980. Localization of a low molecular weight protease inhibitor in the respiratory tract. Bull. Eur. Physiopathol. Respir. 16(Suppl.):231-236.

58. Wiggins, J., J. A. Elliott, R. D. Stevenson, and R. A. Stockley 1982. Effect of corticosteroids on sputum sol-phase protease inhibitors in chronic obstructive pulmonary disease. Thorax. 37:652-656.

59. Ohlsson, K., H. Tegner, and U. Akesson. 1977. Isolation and partial characterization of a low molecular weight acid-stable protease inhibitor from human bronchial secretions. Hoppe-Seyler's Z. Physiol. Chem. 358:583-585.

60. Morihara, K., H. Tsuzuki, and K. Oda. 1979. Protease and elastase of Pseudomonas aeruginosa. Inhibition of human plasma $\alpha_{1}$-proteinase inhibitor. Infect. Immun. 24:188-193.

61. Johnson, D. A., B. Carter-Hamm, and W. M. Dralle. 1982. Inactivation of human bronchial mucosal proteinase inhibitor by Pseudomonas aeruginosa elastase. Am. Rev. Res. Dis. 126:1070-1073.

62. Reimer, A., K. Klementssan, J. Ursing, and B. Wretland. 1980. The mucociliary activity of the respiratory tract. I. Inhibitory effects of products of Pseudomonas aeruginosa on rabbit trachea in vitro. Acta Otolaryngol. 90:462-469.

63. Lyerly, D. M., and A. S. Kreger. 1983. Importance of Serratia protease in the pathogenesis of experimental Serratia marcescens pneumonia. Infect. Immun. 40:113-119.

64. Christensen, T. G., A. L. Korthy, G. L. Snider, and J. A. Hayes. 1977. Irreversible bronchial goblet cell metaplasia in hamsters with elastase-induced panacinar emphysema. J. Clin. Invest. 59:397404.

65. Janoff, A., B. Sloan, G. Weinbaum, V. Damiano, R. A. Sandhaus, and J. Elias. 1977. Experimental emphysema induced with purified human neutrophil elastase: tissue localization of the instilled protease. Am. Rev. Resp. Dis. 115:461-478. 